\title{
DEFORMED WING VIRUS IN Apis mellifera L.: PREVALENCE, MORPHOLOGY, AND PATHOGENICITY
}

\author{
(review)
}

\section{V.E. VOLYKHINA}

S.N. Vyshelesskii Institute of Experimental Veterinary, National Academy of Science of Belarus, 28, ul. Briketa, Minsk, 220003 the Republic of Belarus, e-mail Volykhina@rambler.ru Received November 25, 2014

\begin{abstract}
Viral infections are not considered the most dangerous honeybee (Apis mellifera L.) diseases though being rather harmful. Virus-caused honeybee pathologies are mainly symptomless (N.J. Dimmock et al., 1987; A.C.F. Hung et al., 1996), nevertheless, a rapid replication of the viruses can be triggered leading to clinical manifestation and even death of the insects (R. Singh et al., 2010). In honeybee families a simultaneous circulation of several viruses can occur. Acute bee paralysis virus (ABPV), deformed wing virus (DWV) in Europe, and Kashmir bee virus (KBV), Israeli acute bee paralysis virus (IABPV) and DWV in the United States seem to be related to honeybee family collapse. This review summarizes the data about one of the most prevalent honeybee viruses, DWV (D. Tentcheva et al., 2004; O. Berènyi et al., 2006; S.L. Nielsen et al., 2008; S. Ruba et al., 2012). Surveys showed DWV in European countries. In Austria, France and Denmark the DWV was found in 91,97 and 57\% of the apiaries surveyed; in the Czech Republic 31\% of sampled bees were infected with DWV (note, other viruses in Austria and France were less frequent, i.e. 68 and 58\%, respectively, for ABPV; 49 и $86 \%$ for sacbrood virus, SBV; 30 and $86 \%$ for black queen cell virus, BQCV; and 10 and $28 \%$ for chronic bee paralysis virus, CBPV) (D. Tentcheva et al., 2004; O. Berényi et al., 2006). DWV predominated in the apiaries of all studied regions of Russia (A. Kalashnikov et al., 2012), and in Moscow Province only DWV and SBV were revealed. DWV is detected in Apis florea and A. dorsata (X. Zhang et al., 2012). Free DWV dissemination was indicated among some insects other than Apis (Bombus terrestris, B. pascuorum, B. huntii Green) (E. Genersch et al., 2005; J. Li et al., 2011; A.L. Levitt et al., 2013). DWV, a RNA virus with monocistronic genome, is a member of the genus Iflavirus (Iflaviridae family, Picornavirales) (G. Lanzi et al., 2006). Its phylogenetic relationship with Kakugo virus (T. Fujiyuki et al., 2004; A. Rortais et al., 2006) has been confirmed. The identity of the RNA nucleotide sequences of virus isolates from different geographic locations is 98-99 \% (O. Berènyi et al., 2007). Its structural proteins VP1-3 are similar to the corresponding picornavirus structural proteins, while a low molecular weight protein VP4 is not found (G. Lanzi et al., 2006). The main targets of deformed wing virus are reproductive organs and digestive tract of bees (Y.P. Chen et al., 2006; J. Fievet et al., 2006). The viral RNA is also found in the wings, head, thorax, hemolymph, fat body (J. Fievet et al., 2006; H.F. Boncristiani et al., 2009). It can be detected during all life stages of honeybee (Y.P. Chen et al., 2005). The brood and adults with clinical manifestations of the disease die (L. Bailey et al., 2010). The worker bees are most sensitive to DWV. The bee colonies are weakened; they are characterized by reduced size and prone to sudden collapse (G. Lanzi et al., 2006; R. M. Johnson et al., 2009). The peak incidence is in the autumn. In addition to vector transmission a horizontal per os and also a vertical transovarial transmission of the virus are possible (C. Yue et al., 2005; C. Yue et al., 2007). The virus can cause a latent infection without visible symptoms of the disease with prolonged persistence of the pathogen in the host and vertical virus transmission or subclinical shorter form with high rate of viral replication and more pathogenic horizontal transmission. For clinical outbreak of DWV infection followed by colony collapse a strong trigger is required, such as immunosuppression by mites Varroa destructor or V. destructor as biological vector. The apiaries with V. destructor infestation are often infected by DWV.
\end{abstract}

Keywords: deformed wing virus, honeybee Apis mellifera L., bee family, collapse, virus transmission by vectors, per os transmission, vertical transovarial transmission.

It is currently estimated that there are over 18 viruses capable to infect the Apis mellifera L. honeybee. Although viral infections are not listed among 
the most dangerous honeybee diseases, they may cause significant damage. Acute bee paralysis virus (ABPV) and deformed wing virus (DWV) (the latter is considered to be one of the most common honeybee viruses) in Europe and Kashmir bee virus (KBV), Israeli acute bee paralysis virus (IABPV) and DWV in the United States seem to be related to honeybee family collapse [1].

The viruses are morphologically similar (they have spherical or slightly oval shape and consist of single-stranded RNA enclosed in a 17-30 nm diameter icosahedral protein capsid) and referred to different families of the order Picornavirales [2]. Picornaviruses have no lipid envelope and replicate in the cytoplasm of the contaminated cell. Exclusions are DNA-containing filament virus of ellipsoidal shape [3], icosahedral iridovirus synergic with c Nosema ceranae [4], and RNA-containing chronic paralysis virus of different morphology with polycistronic genome $[5,6]$. Most viral infections are asymptomatic [7, 8], however, in certain conditions, rapid replication of the viruses is possible, which leads to the manifestation of visible disease signs and often to death of honeybees [6]. Simultaneous circulation of several viruses can occur in honeybee families.

Deformed wing virus (DWV) is referred to the family Iflaviridae, genus Iflavirus [9]. It has been noted that this virus is serologically similar to Egypt bee virus [10] and remotely similar to human picornaviruses (poliomyelitis virus, rhinovirus) [11, 12]. DWV prevalence in Apis mellifera L. in European countries is confirmed by the studies carried out by different groups of scientists [13-16]. In Austria and France, DWV was found in 91 and $97 \%$ of the surveyed apiaries, respectively; less frequent are acute bee paralysis virus (ABPV; 68 and 58\%, respectively), sacbrood virus (SBV; 49 and $86 \%$, respectively), black queen cell virus (BQCV; 30 and $86 \%$, respectively) and chronic bee paralysis virus (CBPV; 10 and $28 \%$, respectively) $[13,14]$. The rate of pupa infection in French apiaries was $94 \%$ for DWV, $80 \%$ for SBV, and $23 \%$ for ABPV and BQCV [13]. All apiaries infested by Varroa destructor are contaminated by deformed wing virus. The seasonal variations of DWV prevalence were noted: in spring, summer and autumn, the rate of infection by the virus was 56,66 , and $85 \%$, respectively, for adult bees and 16, 38, and $54 \%$, respectively, for pupae. In apiaries in Denmark, SBV and DWV were primarily identified among six detected viruses (SBV, DWV, ABPV, CBPV, BQCV, KBV) [15].

The predominance of DWV was noted in apiaries in Maikop District of the Republic of Adygeya (Russia); it is followed by sacbrood virus, while black queen cell virus is the rarest (17). In Moscow Region, only DWV and SBV were found. The homology of DWV nucleotide sequences is $98 \%$ [17].

Deformed wing virus was found in Apis florea and A. dorsata [18]. Free virus dissemination was noted among some arthropods not belonging to the genus Apis (Bombus terrestris, B. pascuorum, B. huntii Greene) [19-21].

According to the Baltimore Classification of Viruses, DWV is referred to group IV or (+)ssRNA viruses containing one single-stranded $(+)$ RNA molecule [22]. Such viruses are characterized by the synthesis of (-)RNA which serves as a template for $(+)$ mRNA formation [23]. DWV genetic make-up is similar to that of picornaviruses. The coding sequence of genomic RNA is conventionally divided into three regions: P1 codes structural proteins VP1, VP2, VP3, VP4; P2 and $\mathrm{P} 3$ code the proteins needed for cell reprogramming and replication. The 5 '-end of genomic RNA is covalently bonded to protein VPg (viral protein genome linked) responsible for $5^{\prime}$-end stabilization in replication and translation processes. VPg consists of 23 amino-acid residues. A polyadenylate «tail», poly(A), is attached to the $3^{\prime}$-end. It is followed by a coding sequence flanked by a 5'-untranslated leader sequence (UTR, 1144 nucleotides) and a 3'-untranslated 
region (317 nucleotides). The genomic RNA has a single open reading frame coding polyprotein with the molecular weight of $328 \mathrm{kDa}$. The full viral genome, including the poly(A) «tail», contains 10,140 nucleotides: adenine - $29.5 \%$, uracil $-32.5 \%$, guanine $-22.4 \%$, cytosine $-15.8 \%$. Of single nucleotide polymorphism (SNP), transitions make $82 \%$ [11].

RNA molecule in a DWV particle is surrounded by protein coat. Three basic structural proteins VP1 (44 kDa), VP2 (32 kDa) and VP3 (28 kDa) correspond to structural proteins VP1, VP2 and VP3 in Picornaviridae. Low molecular weight protein similar to protein VP4 located within the capsid of picornaviruses has not been found [11]. The N-terminal region of polyprotein begins with the leader peptide (L-protein) which is more variable than other proteins. It is followed by structural proteins [24]. VP1 and VP3 amino-acid residues are located at polyprotein positions 486-880 and 902-1064, respectively. VP2 aminoacid residues are located to the left of VP1 (positions 256-448). Such boundary line may be hypothetical [11], and a large size of protein VP1 is rather an exclusion. The molecular weight of its homologue does not exceed $35 \mathrm{kDa}$, and more often it is much smaller [25]. Because VP1 is the integral component of the viral particle, it is still an open question how the additional amino acids located at its $\mathrm{C}$-end can fit into the protein coat while not disturbing the spherical shape of the capsid with icosahedral symmetry. The C-terminal region contains the typical picornavirus nonstructural proteins: RNA helicase, chymotrypsin-like 3Cprotease, RNA-dependent RNA polymerase [11]. Maybe, DWV does not use such a translation model when the synthesized giant polypeptide is decomposed by host cell proteases into smaller proteins [10]. It is noted than $28 \%$ of nucleotide substitutions in the coding region lead to changes in amino-acid residues [11]. Insignificant changes in the amino acid composition are sufficient for the manifestation of viral tissue tropism [26, 27].

The identity of nucleotide sequences in the genome of viruses from different geographical areas (Austria, Poland, Germany, Slovenia, Hungary, Nepal, Sri Lanka, UAE, Canada) is $98-99 \%$ [24], or $98 \%$ in case of isolates from Italy and Pennsylvania (USA) [11]. The phylogenetic study revealed the genetic segregation of DWV and Kakugo virus (KV), as well as Varroa destructor virus 1 (VDV-1) [24]. The identity of nucleotide sequences is $84 \%$ for DWV and VDV-1 (28) and 97-98 \% for DWV and KV [9, 29, 30]. The evolutionary relationship of the three viruses has been confirmed. In spite of high homology at a nucleotide level, DWV and KV have distinct structural features [9, 29]: the genome of both viruses is characterized by polymorphism in the assumed leader region associated with viral pathogenesis [11]. It is reported that the combination of the three viruses (VDV-1, DWV and KV) may cause a collapse of honeybee colonies [30].

The main targets of DWV are the reproductive and digestive organs of honeybees [26, 27]. Viral RNA replication was found in samples of wing, head, thorax, leg and intestine biomaterial, as well as in hemolymph [31]. Low virus titer in ovaries contributes to the extension of the latent period [32]. The viral RNA is frequently found in neurocytons, and its presence in glial cells is not ruled out [33]. A strong specific reaction to DWV was registered in the cytoplasm and plasma membrane of most fat body cells [27]. The infection of the fat body, where nutrients are stored, metabolic products are accumulated and antimicrobial peptides are synthesized, can lead to disturbance of physiological processes and weakening of the immune system [34], and have an impact on the production of the main precursor of egg yolk, vitellogenin (monomeric phosphoglycoprotein), the concentration of which in hemolymph correlates with a physiological status of the insect and egg-laying capacity [27, 35]. 
DWV is identified at all development stages of the honeybee [36]. It is noted that infection rate in honeybee families with clear signs of infection is equal to $100 \%$ for adult worker bees, $95 \%$ for pupae, $80 \%$ for larvae and $47 \%$ for adult male bees. Virus titer variability at various honeybee development stages may reflect different capability to resist virus infection.

Deformed wing virus often exists in a latent or subclinical form. The onset of clinical symptoms in infected pupae leads either to their death or appearance of adults with deformed wings [34], distended short abdomens and no pigmentation [10]. Such bees become unviable and die [37]. The honeybee families infected by DWV are weakened, characterized by lesser number due to large reduction in life expectancy [38] and are prone to a sudden collapse [11, 39]. The killed families have much more worker bees with deformed wings as compared to the survived ones [40]. The number of worker bees with visible signs of DWV can be a marker of the upcoming death of the family [40].

In laboratory conditions, DWV introduction directly into the hemolymph of field bees led to greater replication of the virus within the period from day 3 to day 5 after injection [41]. A high degree of infection of different segments (maximum in abdomen, then, in descending order, in thorax and head), worsening of sensory perception, an increase in sensibility to water and low sucrose concentration, and a disorder of associative learning and memory have been noted with the absence of DWV clinical manifestations. Other researchers indicate changes in the behavior of morphologically normal field bees [42]. Such bees exhibit lower learning ability, leave the heave for a longer time and come back less frequently. The question whether deformed wing virus causes the aggressive behavior of bees or not is still disputable. A number of scientists do not associate aggression with the viral infection [9] while others express an opposite opinion [41, 43].

The viral infection combined with mite parasitism in bees causes immunosuppression [44], increased sensitivity to opportunistic pathogenic microorganisms [34], progressive decrease in bee family number and a complex of the diseases which are also determined by other pathogens [13, 45-47]. Mites contribute to wider distribution of the virus in a bee population and increase the DWV titer [1]. The rate of DWV infection positively correlates with mite number and duration of invasion by ectoparasites [40].

The mite parasitism significantly inhibits the gene expression of such antibacterial peptides as abaecin, defensin and hymenoptaecin, and the activity of the enzymes involved in immune response, such as phenol oxidase, glucose dehydrogenase, glucose oxidase and lysozyme [34, 42]; it also leads to an increase in DWV quantity in bees with bacterial infections [34]. The combination of the mite parasitism and presence of DWV and pathogenic microorganisms reduces the survival capacity of bees [48]. Negative correlation between the virus titer and phenol oxidase expression is noted [34]. It is believed that the death of the deformed wing bees infested by mites, which occurred within $24 \mathrm{~h}$, is associated with the insufficient activity of phenol oxidase [48].

There are two hypotheses explaining the negative influence of ectoparasitic mites in case of virus infection. The first one assumes that Varroa destructor mites are biological vectors of DWV [49, 50]. Receiving the virus from infected bees, they accumulate it and then contaminate healthy individuals, in which morphological changes develop or which die within a certain period of time. Positive correlation between the number of the mites parasitizing a particular bee and the manifestation of morphological changes in bees or their death is noted [51]. In infected bees with asymptomatic disease development, DWV titers are 
much lower than in the bees which exhibited the visible signs of the disease or died at the pupa stage. The degree of infestation by mites, rate of virus replication in mites and other factors have an influence on bee infection rate. The detection of viruses in mites and high viral load count in favor of this hypothesis [49, 52, 53]. In the female mites parasitizing infected pupae, the registered DWV titer is several times higher than in the contaminated pupae [51]. In $V$. destructor, picornaviruses were most frequently found in the cytoplasm of midintestine diverticle cells and sometimes in membrane-associated vesicles or long tubular membrane structures of cytoplasm. Q. Zhang et al. [54] believe that such subcellular localization may be an indicator of virus replication. DWV replication in the mid-intestine of mites indicates virus transmission via the hemolymph of infected bees and pupae [55]. In the mites that were able to induce an active form of infection, the number of DWV genome equivalents per individual was $10^{10}-10^{12}$, while in those not causing the visible signs of wing deformation it did not exceed $10^{8}$ [56]. I.e. the development of deformed wings depends not only on $V$. destructor virus transmission, but also on the replication rate and DWV titer in the parasitizing mites. At the same time, the virus has no negative impact neither on the infected female mite, nor its offsprings.

According to the other hypothesis, mites are mechanical vectors. Due to the puncture of the cuticle, they introduce viral particles into bee hemolymph (reinfection). This is confirmed by data on virus reactivation after inoculation [57]. In addition to the mite parasitism, the virus reactivation may be influenced by infection by bacteria and protozoal agents [58], environmental contamination by the chemical compounds harmful to bees [59,60], and other factors.

Epidemiological studies and laboratory experiments have demonstrated a correlation between the virulence of some viruses and the $V$. destructor mites acting as virus distributors between and inside bee colonies, and also as activators of virus reproduction in larvae and adult individuals [61].

Investigating the differences of gene expression in Varroa-sensitive and Varroa-tolerant bee families, M. Navajas et al. [42] concluded that mite parasitism causes changes in the expression of the genes associated with embryonic development, cell metabolism and immunity. The bees resistant to $V$. destructor primarily demonstrated changes in the expression of the genes controlling neuronal sensitivity and olfaction. Differences in olfaction may be due to increased grooming (ectoparasite removal by worker bees) and hygienic behavior (ability of bees to get rid of infected offsprings). The offsprings which are infested by the virulent mites causing visible DWV signs are removed in larger quantity than those infested by less virulent mites or intact offsprings [62]. Selective hygienic behavior (HB) and Varroa sensitive hygiene (VSH) help bees to manage mite parasitism [62, 63]. Interrelations of bees and identification of ill individuals may be influenced by a change in the hydrocarbon profile of the cuticle due to immunostimulation [64]. According to other data [65], on the background of mite parasitism, there is no visible correlation between changes in the hydrocarbon profile of the cuticle and behavior of bees within a social group.

The clinical manifestations of DWV in infected bee families had been attributed to mite parasitism for a long time [66-68] until scientists paid their attention to bees with the typical signs of the disease in the absence of mites $[69,70]$ and to correlation between the development of symptoms and the value of DWV titer [52, 71, 72]. Deformed wing virus can be a major factor of bee family death in the winter period independently from the presence of $V$. destructor mites [73].

J. Iqbal et al. (41) believe that, in natural environment, hemolymph 
infection by $V$. destructor-like mites is the most probable way of DWV transmission. The studies by other scientists indicate that other virus transmission ways exist, too.

The presence of DWV in eggs and larvae at the development stages when infestation by mites was not noted [36, 74, 75], as well as the presence of viral RNA in the queen bee and its reproductive organs $[26,27]$ are indicative of vertical transmission. Among the offsprings from infected queen bees, $\mathrm{DWV}^{+}$eggs, larvae and adult bees constituted 100, 65 and $13 \%$, respectively. The excrements preliminarily taken from such queen bees were $90 \%$ infected, hemolymph and ovaries were $100 \%$ infected, and seminal receptacles were $80 \%$ infected [27]. Laying $\mathrm{DWV}^{+}$eggs by queen bees with infected reproductive organs after artificial insemination confirms a transovarian vertical transmission [76]. The presence of viruses in ovaries and eggs is considered as a firm evidence of such virus transmission [26]. It has been established that the queen bees fertilized by infected sperm laid infertile eggs without $\mathrm{DWV}\left(\mathrm{DWV}^{-}\right)$and $\mathrm{DWV}^{+}$fertile eggs $[76,77]$. Male bees and worker bees of generation $F_{1}$ were also DWV positive.

The horizontal transmission of deformed wing virus to larvae via infected feed is indicated by the infection of hypopharyngeal glands in worker bees [50, 77]. Although the assumption of DWV transmission via infected feed has not been confirmed by experiment (sucrose with virus lysate per os within 7 days), its longer consumption, for example, in winter, may be a source of virus infection [41]. The presence of deformed wing virus in the seminal receptacle assumes veneral horizontal transmission among individuals of one generation during mating [26, 36]. DWV in the epithelial cells of accessory glands and in testicles explains the presence of viral RNA in sperm $[27,77]$. Its intensive replication in seminal vesicles may have a negative impact on the fertility of male bees [27]. In more resistant male bees, the virus was also found in most of the epithelial cells of the proventriculus, proctodeum and in the mature columnar cells of mid-intestine epithelium [27]. The mite parasitism inhibits the spermatogenesis [78].

Thus, deformed wing virus (DWV) is one of the most common viruses of the honeybee, Apis mellifera L. In Austria, France, and Denmark, the virus was found in 91, 97 and $57 \%$ of apiaries, respectively; in the Czech Republic, $31 \%$ of selected honeybees were contaminated by deformed wing virus. DWV prevalence is noted in most of the studied regions of Russia. Deformed wing virus was found in Apis florea and $A$. dorsata. In addition, DWV is spread among the arthropods not belonging to the genus Apis (Bombus terrestris, B. pascuorum, $B$. huntii Greene). DWV is characterized by the monocistronic genome. The virus is identified at all development stages of honeybees, however, worker bees are the most sensitive. Insects with deformed wings are unviable and die. In spite of evolutionary relationship with Kakugo virus, DWV differs from it with regard to virulence, tropism, clinical manifestations and geographical distribution. The identity of genome nucleotide sequences for DWV from different geographical areas is 98-99 \%. DWV itself can cause a latent form of infection (with persistence of the pathogen in the host organism without clinical manifestations and with vertical transmission) or a subclinical form (shorter, with high rate of virus replication and more pathogenic horizontal transmission). An infected family with predominance of individuals without visible signs of the disease and with vertical transmission will normally develop, allowing the virus to exist in the population for a long time. For a clinical outbreak, infection transition to a lethal active form and a subsequent collapse of the bee family, a trigger is required, such as immunosuppression due to the infestation by Varroa destructor or the presence of the mite as a biological vector. 


\section{R E F E R E N C E S}

1. S c h roeder D.C., Marti n S.J. Deformed wing virus. The main suspect in unexplained honeybee deaths worldwide. Virulence, 2012, 3(7): 589-591.

2. C h e n Y.P., S i e d e R. Honey bee viruses. Adv. Virus Res., 2007, 70: 33-80 (doi: 10.1016/S0065-3527(07)70002-7).

3. B a iley L., Carpenter J.M., Woods R.D. Properties of a filamentous virus of the honey bee (Apis mellifera). Virology, 1981, 114(1): 1-7 (doi: 10.1016/0042-6822(81)90247-6).

4. Tok a rz R., Firth C., S tre et C., Cox-Foster D.L. Lack of evidence for an association between Iridovirus and colony collapse disorder. PLOS ONE, 2011, 6(6): e21844 (doi: 10.1371/journal.pone.0021844).

5. Olivier V., Blanchard P., Chaouch S., Lallemand P., Schurr F., Celle O., Dubois E., Tordo N., Thiéry R., Houlgat te R., Ribière M. Molecular characterisation and phylogenetic analysis of Chronic bee paralysis virus, a honey bee virus. $\mathrm{Vi}$ rus Res., 2008, 132(1-2): 59-68 (doi: 10.1016/j.virusres.2007.10.014).

6. Singh R., Levitt A.L., Rajotte E.G., Holmes E.C., Ostiguy N., van Engelsdorp D., Li pkin W.I., d e Pamphilis C.W., Toth A.L., Cox-Fos t e $r$ D. RNA viruses in hymenopteran pollinators: evidence of inter-taxa virus transmission via pollen and potential impact on non-Apis hymenopteran species. PLoS ONE, 2010, 5(12): e14357 (doi: 10.1371/journal.pone.0014357).

7. $\mathrm{D}$ i m m o c k N.J., P ri m ros e S.B. Introduction to modern virology. Primrose, 1987.

8. Hung A.C.F., Shimanuki H., Knox D.A. Inapparent infection of acute bee paralysis virus and Kashmir bee virus in the U.S. honey bees. American Bee Journal, 1996, 136: 874-876.

9. Rortais A., Tentcheva D., Papachristoforou A., Gauthier L., Arnold G., Colin M., B e rg o in M. Deformed wing virus is not related to honey bees' aggressiveness. Virol. J., 2006, 3: 61 (doi: 10.1186/1743-422X-3-61).

10. B a i l e y L., B a 11 B.V. Honey bee pathology. $2^{\text {nd }}$ ed. Academic Press, London, 1991.

11. Lanzi G., de Miranda J.R., Boniotti M.B., Cameron C.E., Lavazza A., Capucci L., Ca mazi ne S.M., Rossi C. Molecular and biological characterization of deformed wing virus of honeybees (Apis mellifera L.). J. Virol., 2006, 80(10): 4998-5009 (doi: 10.1128/JVI.80.10.4998-5009.2006).

12. B a k e r A.C., S ch ro e d e r D.C. The use of RNA-dependent RNA polymerase for the taxonomic assignment of Picorna-like viruses (order Picrornavirales) infecting Apis mellifera L. populations. Virol. J., 2008, 5: 10 (doi: 10.1186/1743-422X-5-10).

13. Tentcheva D., Gauthier L., Zappulla N., Dainat B., Cousserans F., Colin M.E., B ergoin M. Prevalence and seasonal variations of six bee viruses in Apis mellifera L. and Varroa destructor mite populations in France. Appl. Environ. Microbiol., 2004, 70(12): 7185-7191 (doi: 10.1128/AEM.70.12.7185-7191.2004).

14. B erényi O., Bakonyi T., Derakhshifar I., Koglberger H., Nowothy N. Occurrence of six honeybee viruses in diseased Austrian apiaries. Appl. Environ. Microbiol., 2006, 72(4): 2414-2420.

15. $\mathrm{N}$ i e ls e n S.L., $\mathrm{N}$ i c ola i s e $\mathrm{n} \mathrm{M.,} \mathrm{K} \mathrm{ryge} \mathrm{r} \mathrm{P.} \mathrm{Incidence} \mathrm{of} \mathrm{acute} \mathrm{bee} \mathrm{paralysis} \mathrm{virus,} \mathrm{black}$ queen cell virus, chronic bee paralysis virus, deformed wing virus, Kashmir bee virus and sacbrood virus in honey bees (Apis mellifera) in Denmark. Apidologie, 2008, 39: 310-314 (doi: 10.1051/apido:2008007).

16. Ryba S., Titera D., Schodelbauerova-Traxmandlova I., Kindlmann P. Prevalence of honeybee viruses in the Czech Republic and coinfections with other honeybee disease. Biologia, 2012, 67(3): 590-595 (doi: 10.2478/s11756-012-0038-5).

17. Ka lashnikov A.E., Udina I.G. Rasprostranenie RNK-soderzhashchikh virusov u pchely medonosnoi Apis mellifera L. na territorii Rossii. Farm Animals, 2012, 1: 72-76.

18. Zhang X., He S.Y., Evans J.D., Pett is J.S., Y i n G.F., Che n Y.P. New evidence that deformed wing virus and black queen cell virus are multi-host pathogens. J. Invert. Pathol., 2012, 109(1): 156-159 (doi: 10.1016/j.jip.2011.09.010).

19. Genersch E., Yue C., Fries I., de Miranda J.R. Detection of Deformed wing virus, a honey bee viral pathogen, in bumble bees (Bombus terrestris and Bombus pascuorum) with wing deformities. J. Invert. Pathol., 2006, 91(1): 61-63 (doi: 10.1016/j.jip.2005.10.002).

20. Li J., Peng W., Wu J., Strange J.P., B oncristiani H., Chen Y. Cross-species infection of deformed wing virus poses a new threat to pollinator conservation. J. Econom. Entomol., 2011, 104(3): 732-739 (doi: 10.1603/EC10355).

21. Levitt A.L., S ingh R., Cox-Foster D.L., Rajotte E., Hoover K., Ost ig u y N., H ol mes E.C. Cross-species transmission of honey bee viruses in associated arthropods. Virus Res., 2013, 176(1-2): 232-240 (doi: 10.1016/j.virusres.2013.06.013).

22. D i m mork N.J., East o n A.J., Le p p a rd K.N. Introduction to modern virology. $6^{\text {th }}$ ed. Blackwell Publishing, Malden, 2007.

23. S t r a i e r L. Biokhimiya. Tom 3 [Biochemistry. V. 3]. Moscow, 1985.

24. Berenyi O., Bakonyi T., Derakhshifar I., Koglberger H., Topolska G., 
Ritte r W. Phylogenetic analysis of deformed wing virus genotypes from diverse geographic origins indicates recent global distribution of the virus. Appl. Environ. Microbiol., 2007, 73(11): 3605-3611 (doi: 10.1128/AEM.00696-07).

25. Liljas L., Tate J., Lin P., Christian P., Johnson J.E. Evolutionary and taxonomic implications of conserved structural motifs between picornaviruses and insect picornalike viruses. Arch. Virol., 2002, 147: 59-84 (doi: 10.1007/s705-002-8303-1).

26. Che n Y.P., Pet t is J.S., Colli ns A., F e ld la u fer M.F. Prevalence and transmission of honeybee viruses. Appl. Environ. Microbiol., 2006, 72(1): 606-611 (doi: 10.1128/AEM.72.1.606611.2006).

27. Fievet J., Tentcheva D., Gauthier L., De Miranda J.R., Cousserans F., Colin M.E., B e rgoin M. Localization of deformed wing virus infection in queen and drone Apis mellifera L. Virol. J., 2006, 3: 16 (doi: 10.1186/1743-422X-3-16).

28. Ongus J.R., P e ters D., B onmat i n J.M., B engs ch E., V lak J.M., van $\mathrm{O}$ e r s M.M. Complete sequence of a picorna-like virus of the genus Iflavirus replicating in the mite Varroa destructor. J. Gen. Virol., 2004, 85: 3747-3755 (doi: 10.1099/vir.0.80470-0).

29. Fujiyuki T., Take u chi H., Ono M., Ohka S., Sasaki T., Nomoto A., Ku b o T. Novel insect picorna-like virus identified in the brains of aggressive worker honeybees. $J$. Virol., 2004, 78: 1093-1100 (doi: 10.1128/JVI.78.3.1093-1100.2004).

30. Wang H., Xie J., Shreeve T.G., Ma J., Pallett D.W., King L.A., Posse e R.D. Sequence recombination and conservation of Varroa destructor Virus-1 and Deformed Wing Virus in field collected honey bees (Apis mellifera). PIoS ONE, 2013, 8(9): e74508 (doi: 10.1371/journal.pone.0074508).

31. B oncristiani H.F., Di Pris co G., Pett is J.S., Hamilton M., Chen Y.P. Molecular approaches to the analysis of deformed wing virus replication and pathogenesis in the honey bee, Apis mellifera. Virol. J., 2009, 11(6): 221 (doi: 10.1186/1743-422X-6-221).

32. Fus a J.R., Richter A.R. Virulence and multigeneration passage of a nuclear polyhedrosis virus selected for an increased rate of vertical transmission. Biol. Control, 1992, 2: 171-175.

33. Shah K.S., Evans E.C., Pizzorno M.C. Localization of deformed wing virus in the brains of the honeybee, Apis mellifera Linnaeus. Virol. J., 2009, 30(6): 182 (doi: 10.1186/1743422X-6-182).

34. Y a n g X., Cox-F o s t e r D. Impact of an ectoparasite on the immunity and pathology of an invertebrate: evidence for host immunosuppression and viral amplification. PNAS USA, 2005, 102(21): 7470-7475 (doi: 10.1073/pnas.0501860102).

35. E ng e $1 \mathrm{~s} \mathrm{W.} \mathrm{Occurrence} \mathrm{and} \mathrm{significance} \mathrm{of} \mathrm{vitellogenins} \mathrm{in} \mathrm{female} \mathrm{castes} \mathrm{of} \mathrm{social} \mathrm{Hymenoptera.}$ Amer. Zool., 1974, 14: 1229-1237.

36. Che n Y.P., Higg ins J.A., Feld la u fer M.F. Quantitative real-time reverse transcription-PCR analysis of deformed wing virus infection in the honeybee (Apis mellifera L.). Appl. Environ. Microbiol., 2005, 71(1): 436-441 (doi: 10.1128/AEM.71.1.436-441.2005).

37. De Miranda J.R., Genersch E. Deformed wing virus. J. Invert. Pathol., 2010, 103(Suppl. 1): 48-61.

38. K ov a c H., C rails h e i m K. Lifespan of Apis mellifera carnica Pollm infested by Varroa jacobsoni in relation to season and extent of infestation. Journal of Apicultural Research, 1988, 27: 230-238.

39. J o hns o n R.M., Evans J.D., Robinson G.E., B e re nbaum M.R. Changes in transcript abundance relating to colony collapse disorder in honey bees (Apis mellifera). PNAS USA, 2009, 35(106): 14790-14795 (doi: 10.1073/pnas.0906970106).

40. Dainat B., Evans J.D., Chen Y.P., Gauthier L., N e u mann P. Dead or alive: deformed wing virus and Varroa destructor reduce the life span of winter honeybees. Appl. Environ. Microbiol., 2013, 78(4): 981-987 (doi: 10.1128/AEM.06537-11).

41. I q b a 1 J., M u e 11 e r U. Virus infection causes specific learning deficits in honeybee foragers. Proc. Biol. Sci., 2007, 274(1617): 1517-1521 (doi: 10.1098/rspb.2007.0022).

42. Navajas M., Migeon A., Alaux C., Martin-Magniett M., Robinson G., Evans J., Cros-Arteil S., Crauser D., Le Conte Y. Differential gene expression of the honey bee Apis mellifera associated with Varroa destructor infection. BMC Genomics, 2008, 9: 301 (doi: 10.1186/1471-2164-9-301).

43. Terio V., Martella V., Camero M., Decado N., Testini G., Bonerba E., Tantillo G. Detection of a honeybee iflavirus with intermediate characteristics between kakugo virus and deformed wing virus. New Microbiology, 2008, 31(4): 439-444.

44. Enge lhard E.K. The insect tracheal system: A conduit for the systemic spread of Autographa californica M nuclear polyhedrosis virus. PNAS USA, 1994, 91: 3224-3227 (doi: 10.1073/pnas.91.8.3224).

45. B a 11 B.V., A $11 \mathrm{e} \mathrm{n} \mathrm{M.F.} \mathrm{The} \mathrm{prevalence} \mathrm{of} \mathrm{pathogens} \mathrm{in} \mathrm{honey} \mathrm{bee} \mathrm{(Apis} \mathrm{mellifera)} \mathrm{colonies}$ infested with the parasitic mite Varroa jacobsoni. Ann. Appl. Biol., 1988, 113: 237-244 (doi: 10.1111/j.1744-7348.1988.tb03300.x).

46. Shimanuki H., Calderone N.W., Knox D.A. Parasitic mite syndrome: the symptoms. American Bee Journal, 1994, 134: 827-828. 
47. Nordströ m S. Virus infection in Nordic honeybee colonies with no, low or severe Varroa jacobsoni infestations. Apidologie, 1999, 30: 475-484.

48. Yang X., C ox-F o ste r D. Effects of parasitization by Varroa destructor on survivorship and physiological traits of Apis mellifera in correlation with viral incidence and microbial challenge. Parasitology, 2007, 134(Pt 3): 405-412 (doi: 10.1017/S0031182006000710).

49. Prisco G.D., Zhang X., Pennacchio F., Caprio E., Li J., Evans J.D., De grandi-H offman G., Hamilt on M., Chen Y.P. Dynamic of persistent and acute deformed wing virus infection in honey bees, Apis mellifera. Viruses, 2011, 3(12): 2425-2441 (doi: 10.3390/v3122425).

50. Yu e C., Ge ne r s h E. RT-PCR analysis of Deformed wing virus in honey bees (Apis mellifera) and mites (Varroa destructor). J. Gen. Virol., 2005, 86(Pt 12): 3419-3424.

51. B ow e n-W a lke r P.L., M a r t i n S.J., Gun $\mathrm{n} \mathrm{A.} \mathrm{The} \mathrm{transmission} \mathrm{of} \mathrm{deformed} \mathrm{wing} \mathrm{virus}$ between honeybees (Apis mellifera L.) by the ectoparasitic mite varroa jacobsoni. J. Invert. Pathol., 1999, 73(1): 101-106.

52. Tentcheva D., Gauthier L., Jouve S., Canabady-Rochelle L., Dainat B., Cousserans F., Colin M.E., Ball B.V., B e rgo in M. Polymerase chain reaction detection of deformed wing virus (DWV) in Apis mellifera L. and Varroa destructor. Apidologie, 2004, 35: 431-439 (doi: 10.1051/apido:2004021).

53. Bakonyi T., Farkas R., Szendroi A., Dobos-Kovács M., Rusvai M. Detection of acute bee paralysis virus by RT-PCR in honey bee and Varroa destructor field samples: rapid screening of representative Hungarian apiaries. Apidologie, 2002, 33: 63-74 (doi: 10.1051/apido:2001004).

54. Zhang Q., Ongus J.R., B o ot W.J., Calis J., B o n mat in J.M., B eng s ch E. Detection and localization of picorna-like virus particles in tissues of Varroa destructor, an ectoparasite of the honey bee, Apis mellifera. J. Invert. Pathol., 2007, 96(2): 97-105.

55. Sa ntillán-Gali c i a M.T., C a r zaniga R., B a 11 B.V., Ald e rso n P.G. Immunolocalization of deformed wing virus particles within the mite Varroa destructor. J. Gen. Virol., 2008, 89(Pt 7): 1685-1689.

56. G is d e r S., A u me i e r P., G e ne rs h E. Deformed wing virus: replication and viral load in mites (Varroa destructor). J. Gen. Virol., 2009, 90(2): 463-467 (doi: 10.1099/vir.0.005579-0).

57. D a 11 D.J. Inapparent infection of honey bee pupae by Kashmir and sacbrood bee viruses in Australia. Ann. Appl. Biol., 1985, 106: 461-468 (doi: 10.1111/j.1744-7348.1985.tb03136.x).

58. B a i le y L., B a 11 B.V., P e r ry J.N. Association of viruses with two protozoal pathogens of the honey bee. Ann. Appl. Biol., 1983, 103: 13-20 (doi: 10.1111/j.1744-7348.1983.tb02735.x).

59. Charvet R., Kat ouzian-S a fad i M., Colin M.E., M archard P.A., B on $\mathrm{m}$ at i n J.M. Systemic insecticides: new risk for pollinator insects. Annals of Pharmacology Fr., 2004, 62(1): 29-35.

60. Colin M.E., B onmatin J.M., Moineau I., Gaimon C., Brun S., Vermand e re J.P. A method to quantify and analyze the foraging activity of honey bees: relevance to the sublethal effects induced by systemic insecticides. Arch. Environ. Con. Tox., 2004, 47(3): 387-395 (doi: 10.1007/s00244-004-3052-y).

61. Ge nersch E., Aubert M. Emerging and re-emerging viruses of the honey bee (Apis mellifera L). Veterinary Research, 2010, 41(6): 54 (doi: 10.1051/vetres/2010027).

62. Schöning C., Gisder S., Ge is e lhardt S., Krets chmann I., Bienefeld K., Hilker M., Ge nersh E. Evidence for damage-dependent hygienic behaviour towards Varroa destructor-parasitised brood in the western honey bee, Apis mellifera. J. Exp. Biol., 2012, 215(Pt 2): 264-271.

63. Parker P., Guarna M.M., M e lathopoulos A.P., Ky ung-M e M Mo n, White R., Huxter E., Pernal S.F., Foster L.J. Correlation of proteome-wide changes with social immunity behaviors provides insight into resistance to the parasitic mite, Varroa destructor, in the honey bee (Apis mellifera). Genome Biology, 2012, 13(9): R. 81 (doi: 10.1186/gb-2012-13-9-r81).

64. Richard F.J., Holt H.L., Grozinger C.M. Effects of immunostimulation on social behavior, chemical communication and genome-wide gene expression in honey bee workers (Apis mellifera). BMC Genomics, 2012, 13: 558 (doi: 10.1186/1471-2164-13-558).

65. M c Donnell C.M., Alaux C., Parrinello H., Desvignes J.P., Crauser D., Durbesson E., Beslay D. Ecto- and endoparasite induce similar chemical and brain neurogenomic responses in the honey bee (Apis mellifera). BMC Ecology, 2013, 13(1): 25 (doi: 10.1186/1472-6785-13-25).

66. We in berg K.P., Madel G. The influence of the mite Varroa jacobsoni on the protein concentration and the haemolymph volume of the blood of the worker bees and drones of the honey bee Apis mellifera. Apidologie, 1985, 16: 421-436.

67. Daly H.V., D e J o ng D., S t o n e N.D. Effect of parasitism by Varroa jacobsoni on morphometrics of Africanized worker honey-bees. Journal of Apicultural Research, 1988, 27: 126-130.

68. Koch W., Ritter W. Experimental examinations concerning the problem of deformed 
emerging bees after infestation with Varroa jacobsoni. J. Vet. Med., 1991, 38: 337-344.

69. M a r cangeli J., M o nett i L., Fernande z N. Malformations produced by Varroa jacobsoni on Apis mellifera in the province of Buenos Aires, Argentina. Apidologie, 1992, 23: 399-402.

70. Nordström S. Distribution of deformed wing virus within honey bee (Apis mellifera) brood cells infested with the ectoparasitic mite Varroa destructor. Exp. Appl. Acarol., 2003, 29: 293-302.

71. Nordström S. Virus infections and varroa mite infestations in honey bee colonies. PhD thesis. Swedish University of Agricultural Sciences, Sweden, 2000.

72. Chen Y.P., S mith I.B., Collins A.M., Pett is J.S., Feld lau fer M.F. Detection of deformed wing virus infection in honey bees, Apis mellifera L., in the United States. American Bee Journal, 2004, 144: 557-559.

73. Highfield A.C., $\mathrm{Nagar}$ A.E., Mackinder L.C., Noël L.M., Hall M.J., Marti n S.J., S c h ro e de r D.C. Deformed wing virus implicated in overwintering honeybee colony losses. Appl. Environ. Microbiol., 2009, 75(22): 7212-7220 (doi: 10.1128/AEM.02227-09).

74. Che n Y.P., Pet t is J.S., Fe ld la u fer M.F. Detection of multiple viruses in queens of the honey bee Apis mellifera L. J. Invert. Pathol., 2005, 90: 118-121 (doi: 10.1016/j.jip.2005.08.005).

75. D e M i r a nd a J.R., F rie s I. Venereal and vertical transmission of deformed wing virus in honeybees (Apis mellifera L.). J. Invert. Pathol., 2008, 98(2): 184-189 (doi: $10.1016 / \mathrm{j} . j i p .2008 .02 .004)$.

76. Yue C., S chröder M., Gisder S., Ge ne rs ch E. Vertical-transmission routes for deformed wing virus of honeybees (Apis mellifera). J. Gen. Virol., 2007, 88(Pt 8): 2329-2336 (doi: 10.1099/vir.0.83101-0).

77. Yue C., S chröder M., B i e nefeld K., Ge nersch E. Detection of viral sequences in semen of honeybees (Apis mellifera): evidence for vertical transmission of viruses through drones. J. Invert. Pathol., 2006, 92: 105-108 (doi: 10.1016/j.jip.2006.03.001).

78. Calde rón R.A., va n Ve en J.W., S o m meijer M.J., S a n chez L.A. Reproductive biology of Varroa destructor in Africanized honey bees (Apis mellifera). Exp. Appl. Acarol., 2010, 50(4): 281-297 (doi: 10.1007/s10493-009-9325-4). 